\title{
Neighborhood and Individual Sociodemographic Characteristics Associated with Disparities in Adult Obesity and Perceptions of the Home Food Environment
}

\author{
Michael T. Halpern, 2,* Laura C. Arena, Rachel A. Royce, Robin E. Soler, Breda Munoz, and Caitlin M. Hennessy
}

\begin{abstract}
Purpose: Multiple studies have demonstrated significant disparities in the relationship between individual sociodemographic characteristics and risk of overweight or obesity. However, little information is available for assessing the complex associations among being overweight or obese with neighborhood and individual sociodemographic factors and the measured and perceived community food environment.

Methods: Using 2014 national evaluation data from 20 communities (analyzed 2015-2016) that participated in the U.S. Centers for Disease Control and Prevention Community Transformation Grants Program, we used multilevel multivariable models to assess associations among factors at the individual, census tract, and county levels with being overweight or obese and with the perceived home food environment.

Results: Individual level factors (age, sex, race/ethnicity, household income, and education) were significantly associated with the likelihood of being overweight or obese in every model tested. Census tract level poverty and education were significantly associated with the likelihood of being overweight or obese in univariate but not multivariable analyses. Perceived community food environment was a significant predictor of the perceived home food environment; the objective measure of county-level grocery store access was not. Neither perceived nor objective community food environment measures were significantly associated with overweight/obesity in multivariable analyses.

Conclusion: Individual-level sociodemographic characteristics are more strongly associated with obesity-related outcomes than are area-level measures. Future interventions designed to address health equity issues in obesity among underserved populations may benefit from focusing on nutrition education tailored to individuals, to encourage purchase and consumption of healthy food. Improving healthy food availability in underserved communities may also be critical for nutrition education to have a meaningful impact.
\end{abstract}

Keywords: diet; health behavior; health status disparities; obesity; residence characteristics; socioeconomic factors

\section{Introduction}

Substantial disparities in rates of overweight/obesity affect U.S. populations. With more than two-thirds of U.S. adults overweight or obese, ${ }^{1}$ these disparities affect large numbers of individuals. ${ }^{2}$ Geographic and racial/ethnic disparities in overweight and obesity persist even after controlling for factors such as individual income and education, ${ }^{3,4}$ suggesting that area-based interventions such as improving access to healthy foods and opportunities for physical activity may promote healthy weight. ${ }^{5,6}$

Neighborhood social and environmental context (e.g., area-level distribution of race/ethnicity and

${ }^{1}$ RTI International, Social, Statistical, and Environmental Sciences, Research Triangle Park, North Carolina and Washington, DC.

${ }^{2}$ Department of Health Services Administration and Policy, College of Public Health, Temple University, Philadelphia, Pennsylvania.

${ }^{3}$ Division of Community Health, Centers for Disease Control and Prevention, Atlanta, Georgia.

*Address correspondence to: Michael T. Halpern, MD, PhD, RTI International, 701 13th Street NW, Suite 750, Washington, DC 20005, E-mail: mhalpern@rti.org

(c) Michael T. Halpern et al. 2017; Published by Mary Ann Liebert, Inc. This is an Open Access article distributed under the terms of the Creative Commons Attribution License, which permits unrestricted use, distribution, and reproduction in any medium, provided the original work is properly cited. 
education) may correlate independently with available healthy foods and obesity. ${ }^{7-14}$ For example, predominantly minority communities have less access to healthy foods than do predominantly white communities, and neighborhoods with higher percentages of Black or Hispanic residents have higher obesity rates than do mixed or mostly non-Hispanic white neighborhoods. ${ }^{8,15-19}$ Individuals in low-income or predominantly-minority neighborhoods must travel greater distances to reach supermarkets and are exposed to more fast-food restaurants. ${ }^{8,9,18-22}$ These factors may help explain observed disparities associated with weight. For example, Black and White men had similar odds of obesity when adjusting for social and environmental conditions. ${ }^{23}$

Social determinants of health, including environments in which individuals live and work and available economic and social resources, are strongly related to overweight/obesity incidence. ${ }^{24}$ However, results from studies examining associations between neighborhoodlevel factors and individual-level overweight/obesity status while controlling for individual-level sociodemographic characteristics have been mixed. Some have reported significant effects of neighborhood-level poverty on body mass index (BMI) or obesity even when controlling for individual-level characteristics. For example, Dubowitz et al. found a negative association $(p<0.0001)$ between neighborhood socioeconomic status (SES) and BMI/obesity while adjusting for individuallevel factors. ${ }^{10}$ Similarly, Wang et al. reported that even after controlling for individual sociodemographic characteristics, residence in neighborhoods with a preponderance of low socioeconomic residents was associated with increased BMI. ${ }^{25}$

In contrast, other studies found inconsistent or nonsignificant associations with neighborhood-level poverty/education when controlling for individuallevel characteristics. Hutchinson et al., found no significant association between census tract level poverty and relative risk of being overweight/obese; individual-level sex, age, and race were significant predictors. ${ }^{26}$ Drewnowski et al. found that, when controlling for individual sociodemographic characteristics, associations between BMI and neighborhood property values were significant only among women, not among men. ${ }^{27}$ Robert and Reither reported that community-level socioeconomic position was not significantly associated with BMI although individual-level race/ethnicity, age, education, and income were significant predictors of BMI when controlling for area-level factors. ${ }^{28}$
In addition to assessing sociodemographic characteristics potentially related to obesity, it is also important to consider perceptions of the food environment (e.g., perceived availability of healthy food within the home or within a community). Studies have asked about perceived availability or presence of fruits and vegetables in the home or in neighborhood supermarkets as measures of healthy home and community food environments, respectively. Assessment of fruit and vegetable availability is particularly relevant as increased intake of these can be an important weight loss strategy, ${ }^{29,30}$ and fruit and vegetable intake is a common outcome measure in studies of the impact of local food environment on diet. ${ }^{31}$ Perceived home food environment has been assessed using a four- or five-point scale asking how frequently fruits and vegetables are available in the home. ${ }^{32-34}$ These home food environment measures are different from dietary intake measures, which assess how frequently an individual eats certain foods. Perceived community food environment, asking about availability of fruits and vegetables in stores where most groceries are purchased, has been measured using 3-, 4-, or 5-point scales ${ }^{35-43}$; scales have been collapsed to binary variables in some studies. $^{38,43}$ No standardized measure of perceived healthy food availability exists.

Studies have examined relationships between perceptions of home and community food environments and differences in purchasing or consuming healthy foods, ${ }^{35,39,40,42,44}$ which are important predictors of maintaining healthy weight. ${ }^{29,30}$ However, there are mixed findings regarding accuracy of individuals' perceptions and actual availability of supermarkets and healthy food in communities. ${ }^{38,41,42,44-46}$ This underscores the importance of including both objective measures (e.g., county-level grocery stores) and self-reported perceptions of the community food environments as factors potentially affecting overweight/obesity.

The Community Transformation Grants (CTG) Program, led by the U.S. Centers for Disease Control and Prevention (CDC) from 2011 to 2014, supported 35 communities to design and carryout local evidencebased programs to prevent chronic diseases such as cancer, diabetes, and heart disease (www.cdc.gov/nccdphp/ dch/programs/communitytransformation). CDC's national evaluation of the CTG Program included a household survey in 20 communities, collecting primary data from participants on their sociodemographic characteristics (including BMI) and perceived home and community food environments. The objective of this 
report is to assess associations of neighborhood social and economic context and individual-level factors on obesity-related measures using data from the CTG household survey and area-level measures. This study extends previous research using multilevel analyses to examine predictors of perceived home food environment and obesity in a stratified sample of U.S. residents across rural and urban communities.

\section{Methods}

Study design and sample

The CTG Program conducted the Adult Targeted Surveillance Survey (ATSS) in 2013 and 2014 in 20 of 35 funded CTG communities using a protocol approved by the Institutional Review Boards for RTI International and CDC. The ATSS included existing items from national-level surveillance systems, including the Behavioral Risk Factor Surveillance Survey and National Health and Nutrition Examination Survey. The 20 sites included a mixture of large counties, states, and states minus large counties. The large counties were Los Angeles County, CA; Denver County, CO; Broward County, FL; Hennepin County, MN; Jackson County, MO, Jefferson County, KY; Oklahoma County, OK; Philadelphia County, PA; and Travis County, TX. The states were IA, MT, SC, VT, and WV. The states minus large counties ${ }^{\dagger}$ were IL, MD, MA, NC, TX, and WI.

We used address-based sampling to select a stratified simple random sample of 1000 households per site to represent the range of CTG Program geographies and populations.

We collected initial screener information to determine whether a household was eligible to participate based on the presence of an English- or Spanishspeaking adult aged 18 years or older living in the household. Overall $90.8 \%$ of households were eligible (range 79.8-95.0\%). From each eligible household, we randomly selected one adult resident at least 18 years of age to complete the ATSS through a computerassisted telephone interview or a self-administered pencil-and-paper interview. We oversampled Black, Hispanic, and rural residents to increase numbers of completed interviews for those groups. Overall response rate was $24.7 \%$, yielding 22,381 participants. For this report we included 21,531 ATSS participants with no missing values for the main outcome (BMI), $\sim 96 \%$ of respondents.

\footnotetext{
Large counties were defined as those with a population of 500,000 or more.
}

\section{Independent variables}

Individual-level predictors from the ATSS were: age (18-24, 25-34, 35-44, 45-54, 55-64, or 64+ years), sex, race/ethnicity (Hispanic, any race; White, nonHispanic; Black, non-Hispanic; multiracial, nonHispanic; and other, non-Hispanic), annual household income $(<\$ 10,000, \$ 10,000-\$ 14,999, \$ 15,000-\$ 19,999$, $\$ 20,000-\$ 24,999, \$ 25,000-\$ 34,999, \$ 35,000-\$ 49,999$, $\$ 50,000-\$ 74,999$, or $\geq \$ 75,000$ per year), highest educational attainment (never attended, grades $1-8$, grades 9-11, grade 12 or equivalent, college $1-3$ years, or college $\geq 4$ years), and rural/urban status. Due to the low frequency, multiracial, non-Hispanic, and other, nonHispanic groups were combined for analyses; they comprised $5.2 \%$ of respondents. Similarly, we merged the lowest three levels of education into one category, completed high school or less (10.9\% of respondents). Rural/urban status was categorized using the 2006 National Center for Health Statistics Urban-Rural Classification Scheme for Counties, combining four levels for urban counties (large central, large fringe, medium, and small metro) and two for rural counties (micropolitan and noncore). We also included a measure of perceived community food environment, coded as a dichotomous variable based on previously published work using the same dataset. ${ }^{47}$ For this measure, we combined the top two of four ATSS responses of "Strongly agreed" or "Somewhat agreed" to having good availability, affordability, and quality of fruits and vegetables where shopping for food compared to the combined other response categories.

We included three area-level predictors based on respondents' census tract or county of residence. Data from the American Community Survey were used to determine proportions of the census tract population at/below poverty level and with less than high school education. ${ }^{48}$ We obtained a county-level measure of community food environment from the U.S. Department of Agriculture (USDA) Food Environment Atlas: percentage of people in a county living more than one mile from a supermarket/large grocery store if in urban areas or more than 10 miles if in rural areas. ${ }^{49}$ These proportions were categorized into quartiles and assigned to respondents. The lowest quartiles served as the reference groups in multivariable analyses.

\section{Outcome measures}

Respondents reported their height and weight in the ATSS. We used these data to compute BMI. We categorized respondents as overweight/obese with BMI 
$25.0 \mathrm{~kg} / \mathrm{m}^{2}$ or higher. Respondents also characterized the presence of fruit and vegetables in their home on a 5-point scale, similar to previous studies. ${ }^{34} \mathrm{We}$ created a dichotomous secondary outcome variable, perceived home food environment, by combining perceptions of the presence of fruit and vegetables in their home at the two top response choices, "Always" or "Most of the time," compared with other responses.

\section{Statistical analyses}

We used correlation and multilevel (or mixed) logistic models for the two binary outcome measures to evaluate associations between predictors and outcomes. All multilevel predictor variables used in the modeling were entered as indicator variables, whether nominal or ordinal in origin.

We investigated collinearity using variance inflation factor, condition index, variance decomposition proportion, eigenvalues, and full versus reduced model approaches that account for the complex survey design. ${ }^{50-53}$ Remaining predictors did not exhibit major collinearity.

We included three multivariable models for each study outcome measure (overweight/obesity and perceived home food environment). The first model examined individual-level predictors only. The second model added the two census tract level variables (poverty and education). The third included county-level grocery store access, perceived community food environment, and rural/urban status while also controlling for individual-level characteristics. Because the relationship between predictor variables and outcomes was not the same across all census tracts or sites, we used random intercept models and random coefficient models to account for within and between cluster (site and census tract) variability. We used the SUBJECT option in PROC GLIMMIX to account for clustering effects of subjects living in the same site. Analyses used PROC GLIMMIX and PROC MIXED, SAS 9.4 (SAS Institute, Inc., Cary, NC) to account for the complex sample design, distribution of data, and multilevel model. We used a full versus reduced model approach to determine significance of parameters in the final model. Significance was established at $p<0.05$.

\section{Results}

Descriptive statistics

Most respondents included in analyses were aged 45 years or older $(62.6 \%)$, female (66.1\%), non-Hispanic white $(57.2 \%)$, and resided in urban areas $(79.0 \%$;
Table 1). Slightly more than one-fifth (21.8\%) identified as Black and $15.8 \%$ as Hispanic. Nearly one-third (28.8\%) reported high school completion or equivalent as their highest level of educational achievement. Most respondents had annual household incomes $<\$ 35,000$ (54.0\%). Most reported having healthy community food environments (73.0\%) with good availability, affordability, and quality of fruits and vegetables where they shop.

For census tracts in which respondents lived, the median proportion of the population living at or below poverty was $21.2 \%$, and the median proportion with less than high school education was $18.4 \%$.

Across counties of residence for ATSS respondents, most were considered urban (79.0\%). A median of $37.7 \%$ of the county populations had low access to supermarkets/large grocery stores. The USDA countylevel measurement of supermarket/grocery store access did not significantly correlate with survey respondents' perceptions of their community food environment (correlation 0.01288).

The majority $(83.2 \%)$ of respondents reported fruits available at home always or most of the time and $69.1 \%$ reported vegetables available at home always or most of the time. Combining these as the perceived home food environment outcome measure, $63.5 \%$ had both fruits and vegetables always or most of the time available at home. The median BMI was $27.4 \mathrm{~kg} / \mathrm{m}^{2}$ with over a third of the survey respondents characterized as obese/overweight. Overweight/obesity was significantly negatively associated with the home food environment $(p<0.0001)$.

\section{Predictors of overweight/obesity}

Age, sex, race/ethnicity, household income, and educational attainment were significantly associated with overweight/obesity in bivariate analysis and multivariable modeling (model 1, Table 2). Compared to respondents aged 18-24 years, each additional decade of age was significantly associated with greater relative odds of overweight/obesity until ages 64 and older; respondents aged 45-54 and 55-64 years had the greatest odds of being obese (both having odds ratio [OR] 3.1). Black and Hispanic respondents had significantly higher likelihoods of overweight/obesity (ORs 2.0 and 1.7, respectively) than did non-Hispanic Whites. Female respondents had significantly reduced odds of overweight/ obesity (OR 0.8, 95\% confidence interval [CI] 0.7-0.9). Compared with the lowest household income group $(<\$ 10,000)$, most levels of higher household incomes 
Table 1. Characteristics and Descriptive Statistics of 21,531 Adult Respondents from 20 Sites Across the United States

$\%$ or median
$\left(\mathrm{IQR}^{\mathrm{a}}\right)$

Individual characteristics

Obesity

BMl $\mathrm{kg} / \mathrm{m}^{2}$

Obese $(\mathrm{BMI}>30)$

Overweight (BMI 25-29.9)

Age (years)

$18-24$

25-34

$35-44$

$45-54$

$55-64$

$64+$

Sex

Male

Female

Race/ethnicity

Hispanic, any race

White, non-Hispanic

Black, non-Hispanic

Multiracial, non-Hispanic

Other, non-Hispanic

Income

$<\$ 10,000$

$\$ 10,000-\$ 14,999$

$\$ 15,000-\$ 19,999$

$\$ 20,000-\$ 24,999$

$\$ 25,000-\$ 34,999$

$\$ 35,000-\$ 49,999$

$\$ 50,000-\$ 74,999$

$\geq \$ 75,000$

Education

Never attended

Grades 1-8 (elementary)

Grades 9-11 (some high school)

Grades 12 or equivalent (high school graduate)

College 1-3 years (some college)

College $\geq 4$ years (college graduate)

Rural/urban status

Urban

Rural

Census tract level poverty and education

Poverty level of census tract of residence

(\% of population within census tract at or below poverty level)

$0-15 \%$ population at or below poverty level

$15-20 \%$ population at or below poverty level

20-31\% population at or below poverty level

$31-47 \%$ population at or below poverty level

Educational level of census tract of residence

(\% of population within census tract with

less than high school education)

$1-18 \%$ population with less than high school education

$18-29 \%$ population with less than

high school education

29-33\% population with less than high

school education

$33-42 \%$ population with less than high school education

County-level grocery store access

Population, low access to store $(\%)^{c}$

$22.1 \%$

$30.0 \%$

$37.7 \%(26.9-40.1 \%)$
Table 1. Continued

\begin{tabular}{|c|c|}
\hline & $\begin{array}{c}\text { \% or median } \\
\left(\mathrm{IQR}^{\mathrm{a}}\right)\end{array}$ \\
\hline \multicolumn{2}{|l|}{ Healthy eating community environment (food } \\
\hline $\begin{array}{l}\% \text { of respondents who strongly agreed or } \\
\text { somewhat agreed to having good } \\
\text { availability, affordability, and quality } \\
\text { of fruits and vegetables where } \\
\text { respondent shops }\end{array}$ & $73.0 \%$ \\
\hline \multicolumn{2}{|l|}{$\begin{array}{l}\text { Availability of fruits and vegetables where } \\
\text { respondent shops }\end{array}$} \\
\hline Strongly agree & $75.8 \%$ \\
\hline Somewhat agree & $20.1 \%$ \\
\hline Somewhat disagree & $2.8 \%$ \\
\hline Strongly disagree & $1.2 \%$ \\
\hline \multicolumn{2}{|l|}{$\begin{array}{l}\text { Affordability of fruits and vegetables } \\
\text { in places where respondent shops }\end{array}$} \\
\hline Strongly agree & $27.6 \%$ \\
\hline Somewhat agree & $49.5 \%$ \\
\hline Somewhat disagree & $16.3 \%$ \\
\hline Strongly disagree & $6.6 \%$ \\
\hline \multicolumn{2}{|l|}{$\begin{array}{l}\text { Good quality fruits and vegetables in places } \\
\text { where respondent shops }\end{array}$} \\
\hline Strongly agree & $47.1 \%$ \\
\hline Somewhat agree & $44.3 \%$ \\
\hline Somewhat disagree & $6.9 \%$ \\
\hline Strongly disagree & $1.8 \%$ \\
\hline \multicolumn{2}{|l|}{$\begin{array}{l}\text { Healthy eating home environment } \\
\text { (access, availability) }\end{array}$} \\
\hline $\begin{array}{l}\% \text { of respondents who indicated having } \\
\text { fruit and vegetables in the home always } \\
\text { or most of the time }\end{array}$ & $63.5 \%$ \\
\hline \multicolumn{2}{|l|}{ Availability of fruits at home } \\
\hline Always & $55.7 \%$ \\
\hline Most of the time & $27.5 \%$ \\
\hline Sometimes & $12.6 \%$ \\
\hline Rarely or never & $3.5 \%$ \\
\hline Never & $0.7 \%$ \\
\hline \multicolumn{2}{|l|}{ Availability of vegetables at home } \\
\hline Always & $34.5 \%$ \\
\hline Most of the time & $34.6 \%$ \\
\hline Sometimes & $21.3 \%$ \\
\hline Rarely or never & $7 \%$ \\
\hline Never & $2.6 \%$ \\
\hline
\end{tabular}

Evaluation of the context of vulnerability, nutritional context, and obesity. The sample size was 21,531 adults with complete data on all characteristics who were sampled from 20 sites. All data presented in this table are unweighted.

${ }^{\mathrm{a}} \mathrm{IQR}$ is the 25th-75th percentile.

${ }^{\mathrm{b}}$ Rural/urban status was based on the 2006 National Center for Health Statistics Urban-Rural Classification Scheme for Counties, which has six levels: four levels for urban counties (large central, large fringe, medium, and small metro) and two levels for rural counties (micropolitan and noncore).

'The percentage of people in a county living more than one mile from a supermarket or large grocery store if in an urban area or more than 10 miles from a supermarket or grocery store if in a rural area.

$\mathrm{BMI}$, body mass index; IQR, interquartile range.

(continued) had significantly increased odds of overweight/obesity. College graduates had significantly lower odds of overweight/obesity compared with respondents with a high school diploma or less (OR 0.7, 95\% CI 0.6-0.8).

In the second model, we added census tract level poverty and education. Significant associations with 
Table 2. Obesity and Overweight Association with Individual-Level and Area-Level Characteristics in Univariate and Multivariable Models

\begin{tabular}{|c|c|c|c|c|}
\hline Independent variables & $\begin{array}{l}\text { Unadjusted OR } \\
\quad(95 \% \mathrm{Cl})\end{array}$ & $\begin{array}{c}\text { Model } 1 \\
\text { (individual-level } \\
\text { variables only) } \\
\text { OR }(95 \% \mathrm{Cl})\end{array}$ & $\begin{array}{l}\text { Model } 2 \text { (model } 1 \\
\text { plus census } \\
\text { tract poverty and } \\
\text { education) OR } \\
(95 \% \mathrm{Cl})\end{array}$ & $\begin{array}{c}\text { Model } 3 \text { (model } 1 \text { plus } \\
\text { urban/rural status, grocery } \\
\text { store access, and perceived } \\
\text { community food environment) } \\
\text { OR }(95 \% \mathrm{Cl})\end{array}$ \\
\hline \multicolumn{5}{|l|}{ Individual-level predictors } \\
\hline \multicolumn{5}{|l|}{ Age (18-24 years reference) } \\
\hline $25-34$ & $1.7(1.5-2.0)^{*}$ & $1.8(1.3-2.3)^{*}$ & $1.8(1.3-2.3)^{*}$ & $1.6(1.2-2.2)^{*}$ \\
\hline $35-44$ & $2.7(2.3-3.1)^{*}$ & $2.9(2.3-3.5)^{*}$ & $2.9(2.3-3.5)^{*}$ & $2.8(2.2-3.5)^{*}$ \\
\hline $45-54$ & $2.9(2.5-3.4)^{*}$ & $3.1(2.6-3.8)^{*}$ & $3.1(2.6-3.8)^{*}$ & $3.3(2.8-4.0)^{*}$ \\
\hline $55-64$ & $3.1(2.6-3.5)^{*}$ & $3.1(2.3-4.0)^{*}$ & $3.1(2.3-4.0)^{*}$ & $3.0(2.2-3.9)^{*}$ \\
\hline$>64$ & $2.5(2.1-2.9)^{*}$ & $2.7(2.2-3.3)^{*}$ & $2.7(2.2-3.3)^{*}$ & $2.7(2.2-3.3)^{*}$ \\
\hline \multicolumn{5}{|l|}{ Sex (male reference) } \\
\hline Female & $0.8(0.7-0.9)^{*}$ & $0.8(0.7-0.9)^{*}$ & $0.8(0.7-0.9)^{*}$ & $0.9(0.7-1.0)$ \\
\hline \multicolumn{5}{|c|}{ Race/ethnicity (White, non-Hispanic reference) } \\
\hline Black, non-Hispanic & $2.0(1.9-2.2)^{*}$ & $2.0(1.7-2.4)^{*}$ & $2.0(1.7-2.4)^{*}$ & $2.0(1.6-2.4)^{*}$ \\
\hline Hispanic, any race & $1.6(1.4-1.7)^{*}$ & $1.7(1.3-2.2)^{*}$ & $1.7(1.3-2.2)^{*}$ & $1.7(1.4-2.2)^{*}$ \\
\hline Other & $1.1(1.0-1.3)$ & $1.1(0.9-1.4)$ & $1.1(0.9-1.4)$ & $1.2(1.0-1.6)$ \\
\hline \multicolumn{5}{|l|}{ Household income $(<\$ 10,000$ reference) } \\
\hline$\$ 10,000-\$ 14,999$ & $1.1(1.0-1.3)$ & $1.3(1.02-1.5)^{*}$ & $1.3(1.02-1.5)^{*}$ & $1.1(0.9-1.4)$ \\
\hline$\$ 15,000-\$ 19,999$ & $1.1(1.0-1.3)$ & $1.4(1.2-1.7)^{*}$ & $1.4(1.2-1.7)^{*}$ & $1.3(1.2-1.6)^{*}$ \\
\hline$\$ 20,000-\$ 24,999$ & $1.1(1.0-1.3)$ & $1.1(0.9-1.5)$ & $1.1(0.9-1.5)$ & $1.2(0.9-1.6)$ \\
\hline$\$ 25,000-\$ 34,999$ & $1.0(0.9-1.2)$ & $1.2(1.0-1.5)$ & $1.2(1.0-1.5)$ & $1.2(1.0-1.5)$ \\
\hline$\$ 35,000-\$ 49,999$ & $1.0(0.9-1.2)$ & $1.4(1.03-1.8)^{*}$ & $1.4(1.03-1.8)^{*}$ & $1.4(1.0-2.0)$ \\
\hline$\$ 50,000-\$ 74,999$ & $0.9(0.8-0.99)^{*}$ & $1.3(1.1-1.5)^{*}$ & $1.3(1.1-1.5)^{*}$ & $1.4(1.1-1.7)^{*}$ \\
\hline$\geq \$ 75,000$ & $0.8(0.7-0.9)^{*}$ & $1.3(1.0-1.6)^{*}$ & $1.3(1.04-1.6)^{*}$ & $1.3(1.0-1.8)$ \\
\hline \multicolumn{5}{|l|}{ Education (high school or less reference) } \\
\hline College $1-3$ years (some college) & $1.0(0.9-1.0)$ & $1.0(0.9-1.2)$ & $1.0(0.9-1.2)$ & $1.1(0.9-1.3)$ \\
\hline College $\geq 4$ years (college graduate) & $0.6(0.5-0.6)^{*}$ & $0.7(0.6-0.8)^{*}$ & $0.7(0.6-0.8)^{*}$ & $0.7(0.6-0.9)^{*}$ \\
\hline \multicolumn{5}{|c|}{ Census tract level predictors: poverty and education } \\
\hline \multicolumn{5}{|c|}{$\%$ of population in census tract of residence at or below poverty level ( $0-15 \%$ reference) } \\
\hline $15-20 \%$ & $1.1(1.1-1.2)^{*}$ & & $0.9(0.8-1.1)$ & \\
\hline $20-31 \%$ & $1.3(1.2-1.5)^{*}$ & & $0.9(0.6-1.1)$ & \\
\hline $31-47 \%$ & $1.2(1.1-1.3)^{*}$ & & $0.8(0.6-1.1)$ & \\
\hline \multicolumn{5}{|c|}{$\%$ of population in census tract of residence with less than high school education ( $1-18 \%$ reference) } \\
\hline $18-29 \%$ & $1.5(1.3-1.6)^{*}$ & & $1.3(1.1-1.7)^{*}$ & \\
\hline $29-33 \%$ & $1.3(1.2-1.4)^{*}$ & & $1.2(0.9-1.8)$ & \\
\hline $33-42 \%$ & $1.4(1.3-1.6)^{*}$ & & $1.2(0.8-1.6)$ & \\
\hline \multicolumn{5}{|c|}{ Individual-level urban/rural status ${ }^{\mathrm{a}}$ (rural reference) } \\
\hline Urban & $1.1(1.0-1.1)$ & & & $0.81(0.70-0.95)^{*}$ \\
\hline $\begin{array}{l}\text { County-level predictor: population, } \\
\text { low access to store }(\%)^{\mathrm{b}}\end{array}$ & $1.0(1.0-1.0)$ & & & $1.0(1.0-1.0)$ \\
\hline 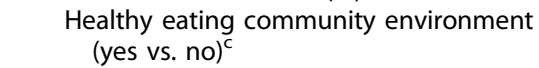 & $0.92(0.86-0.98)^{*}$ & & & $1.0(1.0-1.0)$ \\
\hline
\end{tabular}

The sample size was 21,531 adults with complete data on all characteristics who were sampled from 20 sites. Obesity and overweight defined as BMI of $25 \mathrm{~kg} / \mathrm{m}^{2}$ or higher calculated from self-reported height and weight. Logistic multivariable model of the likelihood of being obese or overweight includes the independent variables listed in each column.

*Indicates statistical significance $(p<0.05)$.

${ }^{a}$ Rural/urban status was based on the 2006 National Center for Health Statistics Urban-Rural Classification Scheme for Counties (see Methods).

${ }^{\mathrm{b}}$ The percentage of people in a county living more than one mile from a supermarket or large grocery store if in an urban area, or more than 10 miles from a supermarket or grocery store if in a rural area.

'The perceived healthy eating community food environment is based on self-reported data from respondents who indicated they "Strongly agreed" or "Somewhat agreed" to having good availability, affordability, and quality of fruits and vegetables where he or she shopped for food.

$\mathrm{Cl}$, confidence interval; $\mathrm{OR}$, odds ratio.

individual-level variables remained consistent with model 1 (model 2, Table 2). Census tract level poverty was not a significant predictor of overweight/obesity, and only one quartile for low educational attainment was significantly associated with overweight/obesity. Finally, in model 3 we included rural/urban status and two community food environment variables (per- ceived community food environment and objectivelymeasured access to grocery stores). Odds of overweight/obesity were significantly decreased among respondents in urban areas (OR 0.8, 95\% CI 0.7-0.95; model 3, Table 2). Neither access to grocery stores nor perceived community food environment was significantly associated with overweight/obesity. 


\section{Predictors of perceived home food environment}

In the first model of perceived healthy home food environment, which contained only individual-level variables, respondents older than 64 were significantly more likely than 18-24 year olds (OR 1.4, 95\% CI 1.2-1.7) and females were significantly more likely than males (OR 1.4, 95\% CI 1.2-1.6) to report healthy home food environments (model 1, Table 3). Com- pared with non-Hispanic whites, Black and other race respondents had significantly increased odds of reporting healthy home food environments (OR 1.3 for both). In comparison to the lowest household income group $(<\$ 10,000)$, respondents in higher income groups were significantly more likely to report healthy home food environments (OR 2.7, 95\% CI 2.4-3.1 for households with an annual income of $\geq \$ 75,000$ per year).

Table 3. Healthy Eating Home Environment Association with Individual-Level and Area-Level Characteristics in Univariate and Multivariable Models

\begin{tabular}{|c|c|c|c|c|}
\hline Independent variables & $\begin{array}{l}\text { Unadjusted OR } \\
\quad(95 \% \mathrm{Cl})\end{array}$ & $\begin{array}{c}\text { Model } 1 \\
\text { (individual-level } \\
\text { variables only) } \\
\text { OR (95\% Cl) }\end{array}$ & $\begin{array}{c}\text { Model } 2 \text { (model } 1 \\
\text { plus census tract } \\
\text { poverty and education) } \\
\text { OR }(95 \% \mathrm{Cl})\end{array}$ & $\begin{array}{c}\text { Model } 3 \text { (model } 1 \text { plus } \\
\text { urban/rural status, grocery } \\
\text { store access, and perceived } \\
\text { community food } \\
\text { environment) OR }(95 \% \mathrm{Cl})\end{array}$ \\
\hline \multicolumn{5}{|l|}{ Individual-level predictors } \\
\hline \multicolumn{5}{|l|}{ Age (18-24 years reference) } \\
\hline $25-34$ & $1.5(1.3-1.7)^{*}$ & $1.0(0.8-1.3)$ & $1.0(0.8-1.3)$ & $1.0(0.8-1.3)$ \\
\hline $35-44$ & $1.5(1.3-1.8)^{*}$ & $1.0(0.8-1.4)$ & $1.0(0.8-1.4)$ & $1.1(0.7-1.6)$ \\
\hline $45-54$ & $1.5(1.3-1.8)^{*}$ & $1.1(0.9-1.5)$ & $1.1(0.9-1.5)$ & $1.2(0.8-1.7)$ \\
\hline $55-64$ & $1.5(1.3-1.8)^{*}$ & $1.3(1.0-1.7)$ & $1.3(1.0-1.7)$ & $1.3(0.9-1.9)$ \\
\hline$>64$ & $1.7(1.4-1.9)^{*}$ & $1.4(1.2-1.7)^{*}$ & $1.4(1.2-1.7)^{*}$ & $1.3(1.02-1.7)^{*}$ \\
\hline \multicolumn{5}{|l|}{ Sex (male reference) } \\
\hline Female & $1.3(1.2-1.3)^{*}$ & $1.4(1.2-1.6)^{*}$ & $1.4(1.2-1.6)^{*}$ & $1.4(1.2-1.6)^{*}$ \\
\hline \multicolumn{5}{|c|}{ Race/ethnicity (White, non-Hispanic reference) } \\
\hline Black, non-Hispanic & $1.2(1.1-1.3)^{*}$ & $1.3(1.1-1.6)^{*}$ & $1.3(1.1-1.6)^{*}$ & $1.3(1.02-1.6)^{*}$ \\
\hline Hispanic, any race & $1.0(0.9-1.0)$ & $1.1(0.9-1.4)$ & $1.1(0.9-1.4)$ & $1.1(0.9-1.4)$ \\
\hline Other & $1.2(1.03-1.4)^{*}$ & $1.3(1.1-1.6)^{*}$ & $1.3(1.1-1.6)^{*}$ & $1.4(1.1-1.7)^{*}$ \\
\hline \multicolumn{5}{|l|}{ Household income $(<\$ 10,000$ reference) } \\
\hline$\$ 10,000-\$ 14,999$ & $1.3(1.1-1.4)^{*}$ & $1.4(1.2-1.6)^{*}$ & $1.4(1.2-1.6)^{*}$ & $1.4(1.2-1.7)^{*}$ \\
\hline$\$ 15,000-\$ 19,999$ & $1.3(1.2-1.5)^{*}$ & $1.2(1.02-1.5)^{*}$ & $1.2(1.0-1.5)^{*}$ & $1.3(1.1-1.6)^{*}$ \\
\hline$\$ 20,000-\$ 24,999$ & $1.4(1.2-1.6)^{*}$ & $1.4(1.1-1.8)^{*}$ & $1.4(1.1-1.8)^{*}$ & $1.4(1.1-1.9)^{*}$ \\
\hline$\$ 25,000-\$ 34,999$ & $1.5(1.3-1.7)^{*}$ & $1.6(1.3-2.0)^{*}$ & $1.6(1.3-2.0)^{*}$ & $1.7(1.3-2.2)^{*}$ \\
\hline$\$ 35,000-\$ 49,999$ & $1.7(1.5-1.9)^{*}$ & $1.7(1.4-2.1)^{*}$ & $1.7(1.4-2.1)^{*}$ & $1.6(1.2-2.0)^{*}$ \\
\hline$\$ 50,000-\$ 74,999$ & $2.1(1.9-2.4)^{*}$ & $2.3(2.0-2.7)^{*}$ & $2.3(2.0-2.7)^{*}$ & $2.2(1.7-2.8)^{*}$ \\
\hline$\geq \$ 75,000$ & $2.9(2.6-3.3)^{*}$ & $2.7(2.4-3.1)^{*}$ & $2.7(2.4-3.1)^{*}$ & $2.5(2.0-3.0)^{*}$ \\
\hline \multicolumn{5}{|c|}{ Education (high school or less reference) } \\
\hline College $1-3$ years (some college) & $1.4(1.3-1.5)^{*}$ & $1.2(1.03-1.3)^{*}$ & $1.2(1.03-1.3)^{*}$ & $1.3(1.1-1.5)^{*}$ \\
\hline College $\geq 4$ years (college graduate) & $2.0(1.9-2.2)^{*}$ & $1.7(1.4-2.0)^{*}$ & $1.7(1.4-2.0)^{*}$ & $1.8(1.5-2.2)^{*}$ \\
\hline \multicolumn{5}{|c|}{ Census tract level predictors: poverty and education } \\
\hline \multicolumn{5}{|c|}{$\%$ of population in census tract of residence at or below poverty level ( $0-15 \%$ reference) } \\
\hline $15-20 \%$ & $0.6(0.6-0.7)^{*}$ & & $0.7(0.6-0.8)^{*}$ & \\
\hline $20-31 \%$ & $0.8(0.8-0.9)^{*}$ & & $0.9(0.7-1.1)$ & \\
\hline $31-47 \%$ & $1.0(0.9-1.1)$ & & $1.0(0.8-1.3)$ & \\
\hline \multicolumn{5}{|c|}{$\%$ of population in census tract of residence with less than high school education ( $1-18 \%$ reference) } \\
\hline $18-29 \%$ & $0.8(0.7-0.8)^{*}$ & & $1.0(0.9-1.2)$ & \\
\hline $29-33 \%$ & $1.0(0.9-1.0)$ & & $1.0(0.8-1.3)$ & \\
\hline $33-42 \%$ & $1.0(0.9-1.0)$ & & $1.1(0.9-1.4)$ & \\
\hline \multicolumn{5}{|c|}{ Individual-level urban/rural status ${ }^{\mathrm{a}}$ (rural reference) } \\
\hline Urban & $1.0(1.0-1.1)$ & & & $1.1(0.9-1.2)$ \\
\hline $\begin{array}{l}\text { County-level predictor: population, } \\
\text { low access to grocery stores (\%) }\end{array}$ & $1.0(1.0-1.0)$ & & & $1.0(1.0-1.0)$ \\
\hline $\begin{array}{l}\text { Healthy eating community } \\
\text { environment (yes vs. no) }\end{array}$ & $1.5(1.4-1.6)^{*}$ & & & $1.5(1.3-1.7)^{*}$ \\
\hline
\end{tabular}

The sample size was 21,531 adults with complete data on all characteristics who were sampled from 20 sites. Healthy eating home environment based on self-reported data from respondents who indicated having fruit and vegetables in the home always or most of the time. Logistic multivariable model of the likelihood of having a healthy eating home environment includes the independent variables listed in each column.

*Indicates statistical significance $(p<0.05)$.

${ }^{a}$ Rural/urban status was based on the 2006 National Center for Health Statistics Urban-Rural Classification Scheme for Counties (see Methods).

${ }^{\mathrm{b}}$ The percentage of people in a county living more than one mile from a supermarket or large grocery store if in an urban area, or more than 10 miles from a supermarket or grocery store if in a rural area.

'The perceived healthy eating community food environment is based on self-reported data from respondents who indicated that they "Strongly agreed" or "Somewhat agreed" to having good availability, affordability, and quality of fruits and vegetables where he or she shopped for food. 
Respondents with some college and college graduates were also significantly more likely to report healthy home food environments compared with respondents with high school diplomas or less (OR 1.2, 95\% CI 1.03-1.3 and OR 1.7, 95\% CI 1.4-2.0, respectively).

The addition of census tract level characteristics in model 2 (respondent's census tract poverty and education) did not alter associations with individual-level variables (model 2 , Table 3 ). In model 2 , only one of the census tract poverty levels (15-20\% of the population at/below poverty) indicated a significantly lower odds of a healthy home food environment (OR 0.7, 95\% CI 0.6-0.8).

In model 3, objectively-measured access to grocery stores was not significantly associated with healthy home food environments. However, respondents who reported healthy community food environments had significantly higher odds of reporting healthy home food environments (OR 1.5, 95\% CI 1.3-1.7). Individual-level variables remained significant (model 3, Table 3).

\section{Discussion}

This large, geographically diverse household survey showed that individual-level sociodemographic characteristics, including age, sex, race/ethnicity, income, and education, independently predicted both being overweight/obese and having a perceived healthy home food environment. An objective area-level measure of community food environment, grocery store access, was not a significant predictor of home food environment or obesity when controlling for the individuallevel characteristics. Perceived community food environment was a significant predictor of perceived home food environment but not of overweight/obesity status. Previous research has similarly reported a significant association between individual-level sociodemographic characteristics and BMI even when controlling for neighborhood characteristics. ${ }^{54}$ These results are also similar to those from two studies by Dubowitz et al., which did not find significant relationships between obesity/BMI and either perceived neighborhood access to healthy foods or of objective measures of distance to full-service supermarkets. ${ }^{36,55}$

While the present study included obesity as an outcome measure, previous studies have more frequently examined predictors of self-reported healthy eating, particularly fruit and vegetable consumption, as outcomes. Findings on associations of objective measures of community food environment and healthy eating behaviors have been mixed. ${ }^{31}$ While some studies have reported results parallel to those of the present study, with no significant association between objective community food access measures and healthy eating, ${ }^{39,44,55}$ others have shown a significant relationship. ${ }^{42,43}$ In addition, Dubowitz et al. reported a significant association between neighborhood SES and fruit and vegetable intake. ${ }^{14}$ In the present study, low census tract SES (education or poverty) was generally not significantly associated with study outcomes in multivariable models.

Research examining the relationship of perceived community food environment with healthy eating also shows mixed findings. Similar to the finding of the present study, showing no significant association between perceived community food environment and obesity, some studies have reported no association of perceived neighborhood food environment with fruit and vegetable consumption. ${ }^{34,36,37}$ In contrast, other studies have indicated that perceptions of the community food environment are associated with increased healthy food consumption. ${ }^{35,40,42-44}$ These differences may reflect differences in outcome measures, that is, obesity in the present study versus self-reported fruit and vegetable consumption in previous research, and differences in questions used to assess perceptions of healthy food availability. Other researchers have highlighted the need to develop standardized measures for assessing perceived availability of healthy foods, as this has been inconsistently measured across different studies. $^{31}$ Standardized assessment of both community-based and home-based food perceptions remains a priority.

Study findings also indicate the importance of controlling for individual-level sociodemographic characteristics when examining associations of arealevel measures with obesity-related outcomes. Census tract level education or poverty was associated with increased likelihood of being obese/overweight or of reporting a healthy home food environment in univariate analyses only; these associations were largely nonsignificant when controlling for individual characteristics.

These findings may assist federal funders and community program staff in reducing overweight/obesity disparities and advance health equity. Our results suggest that interventions to encourage healthy eating behaviors should be tailored to individuals' sociodemographic characteristics (e.g., age, race/ethnicity, and household income) rather than to their neighborhood characteristics. Other researchers have also highlighted 
the importance of attention to specific individual sociodemographic characteristics for dietary interventions, particularly those addressing sugar-sweetened beverages, added sugars, and discretionary fats. ${ }^{56}$ While starting overweight/obesity prevention/reduction efforts in neighborhoods with high proportions of individuals from racial/ethnic minorities or low SES will likely enhance efficiencies in recruiting members of targeted populations, individual characteristics of potential participants should be considered when developing interventions.

CTG communities implemented several interventions to improve availability of healthy foods in neighborhoods (e.g., supporting sales and labeling of healthy food options at corner stores) and address individuallevel characteristics at neighborhood levels (e.g., supporting use of Supplemental Nutrition Assistance Program/Special Supplemental Nutrition Program for Women, Infants and Children [SNAP/WIC] and Electronic Benefits Transfer [EBT] cards at farmers' markets; improving availability of healthy foods in schools and hospitals). Because perceptions of healthy community food environments were significantly associated with perceptions of healthy home food environments, these results also support future initiatives to improve availability of healthy foods in underserved communities. While education about the importance of healthy eating to prevent/reduce obesity is critical, such education cannot be implemented if healthy foods are not available. Nutrition education is an important component for purchasing and consuming healthy foods, especially among disadvantaged groups. ${ }^{57}$

There are a number of limitations associated with this study. All survey data were self-reported; no attempt was made to validate BMI, which could be subject to social desirability or other biases. Measures used to define perceived healthy community and home food environments were each based on a single food type (fruits and vegetables) and cannot capture a complete picture of respondents' community and home food environments. As we collected cross-sectional data only, we were unable to examine potential effects of nutrition-related interventions or changes in the food environment on study outcomes over time. While analyses controlled for clustering by site and included weights to provide estimates for a representative population, there were differences by site in response frequencies. In addition, 15 of the 20 sites represented large counties or multicounty areas; county-level data like those used in this analysis may not be representative of the neighborhoods in which participants resided.

\section{Conclusion}

Despite these limitations, this study extends previous research by examining individual-level and area-level predictors of adult obesity and perceived home food environment in multiple communities using data from a household survey. Our large sample size, including data from multiple geographic regions and use of multilevel analyses, strengthen results compared with previous studies focusing on only one city or region and including relatively few individuals. Our findings suggest that individual-level socioeconomic characteristics are the most important factors in providing information on associations with disparities in overweight/ obesity and perceived home food environments. Future research should explore the utility of developing and implementing programs to reduce obesity-related disparities that are tailored more to characteristics of individuals rather than assuming uniform participant characteristics across an entire neighborhood. In addition, programs should be developed and implemented in combination with efforts to improve availability of healthy foods.

\section{Acknowledgments}

The authors thank Youlian Liao from the Centers for Disease Control and Prevention (CDC) and Robert Stephens from ICF International for providing guidance on the analyses for this article. The findings and conclusions presented in this study are those of the authors and do not necessarily represent the official position of the CDC. This research was supported with funding from the CDC contract number 2002011-F-42078.

\section{Author Disclosure Statement}

No competing financial interests exist.

\section{References}

1. Centers for Disease Control and Prevention. Obesity and overweight. Available at www.cdc.gov/nchs/fastats/obesity-overweight.htm Accessed March 3, 2017.

2. Flegal KM, Kit BK, Orpana $\mathrm{H}$, et al. Association of all-cause mortality with overweight and obesity using standard body mass index categories: a systematic review and meta-analysis. JAMA. 2013;309:71-82.

3. Patterson PD, Moore CG, Probst JC, et al. Obesity and physical inactivity in rural America. J Rural Health. 2004;20:151-159.

4. Centers for Disease Control and Prevention. CDC health disparities \& inequalities report: United States, 2011. MMWR Morb Mortal Wkly Rep. 2011;S60:73-77. 
5. Morland K, Diez Roux AV, Wing S. Supermarkets, other food stores, and obesity: the atherosclerosis risk in communities study. Am J Prev Med. 2006;30:333-339.

6. Gordon-Larsen $\mathrm{P}$, Nelson $\mathrm{MC}$, Page $\mathrm{P}$, et al. Inequality in the built environment underlies key health disparities in physical activity and obesity Pediatrics. 2006:117:417-424.

7. Zeigler-Johnson C, Weber A, Glanz K, et al. Gender- and ethnic-specific associations with obesity: individual and neighborhood-level factors. J Natl Med Assoc. 2013;105:173-182.

8. Baker EA, Schootman M, Barnidge $E$, et al. The role of race and poverty in access to foods that enable individuals to adhere to dietary guidelines. Prev Chronic Dis. 2006;3:A76.

9. Richardson AS, Boone-Heinonen J, Popkin BM, et al. Are neighbourhood food resources distributed inequitably by income and race in the USA? Epidemiological findings across the urban spectrum. BMJ Open. 2012;2:e000698.

10. Dubowitz T, Ghosh-Dastidar M, Eibner C, et al. The Women's Health Initiative: the food environment, neighborhood socioeconomic status, BMI and blood pressure. Obesity (Silver Spring). 2012;20:862-871.

11. Zick C, Smith KR, Fan JX, et al. Running to the store? The relationship between neighborhood environments and the risk of obesity. Soc Sci Med. 2009;69:1493-1500.

12. Franco M, Diez Roux AV, Glass TA, et al. Neighborhood characteristics and availability of healthy foods in Baltimore. Am J Prev Med. 2008;35:561-567.

13. Kirby JB, Liang L, Chen $\mathrm{HJ}$, et al. Race, place, and obesity: the complex relationships among community racial/ethnic composition, individual race/ethnicity, and obesity in the United States. Am J Public Health. 2012;102:1572-1578.

14. Dubowitz T, Heron M, Bird CE, et al. Neighborhood socioeconomic status and fruit and vegetable intake among whites, blacks, and Mexican Americans in the United States. Am J Clin Nutr. 2008;87: 1883-1891.

15. Bower KM, Thorpe RJ Jr, Rohde C, et al. The intersection of neighborhood racial segregation, poverty, and urbanicity and its impact on food store availability in the United States. Prev Med. 2014;58:33-39.

16. Corral I, Landrine H, Zhao L. Residential segregation and obesity among a national sample of Hispanic adults. J Health Psychol. 2014;19: 503-508.

17. Larson NI, Story MT, Nelson MC. Neighborhood environments: disparities in access to healthy foods in the U.S. Am J Prev Med. 2009;36: 74-81.

18. Powell LM, Chaloupka FJ, Bao Y. The availability of fast-food and fullservice restaurants in the United States: associations with neighborhood characteristics. Am J Prev Med. 2007;33(4 Suppl):S240-S245.

19. Wilson DK, Kirtland KA, Ainsworth BE, et al. Socioeconomic status and perceptions of access and safety for physical activity. Ann Behav Med. 2004;28:20-28.

20. Block JP, Scribner RA, DeSalvo KB. Fast food, race/ethnicity, and income: a geographic analysis. Am J Prev Med. 2004;27:211-217.

21. Kwate NO, Yau CY, Loh JM, et al. Inequality in obesigenic environments: fast food density in New York City. Health Place. 2009;15: 364-373.

22. Sharkey JR, Horel S, Han D, et al. Association between neighborhood need and spatial access to food stores and fast food restaurants in neighborhoods of colonias. Int J Health Geogr. 2009;8:9.

23. Thorpe RJ Jr, Kelley E, Bowie JV, et al. Explaining racial disparities in obesity among men: does place matter? Am J Mens Health. 2015;9: 464-472.

24. Regan G, Lee RE, Booth $\mathrm{K}$, et al. Obesogenic influences in public housing a mixed-method analysis. Am J Health Promot. 2006;20:282-290.

25. Wang MC, Kim S, Gonzalez AA, et al. Socioeconomic and food-related physical characteristics of the neighbourhood environment are associated with body mass index. J Epidemiol Community Health. 2007;61: 491-498.

26. Hutchinson PL, Nicholas Bodor J, Swalm CM, et al. Neighbourhood food environments and obesity in southeast Louisiana. Health Place. 2012;18:854-860.

27. Drewnowski A, Aggarwal A, Rehm CD, et al. Environments perceived as obesogenic have lower residential property values. Am J Prev Med. 2014;47:260-274.
28. Robert SA, Reither EN. A multilevel analysis of race, community disadvantage, and body mass index among adults in the US. Soc Sci Med. 2004;59:2421-2434.

29. Rolls BJ, Ello-Martin JA, Tohill BC. What can intervention studies tell us about the relationship between fruit and vegetable consumption and weight management? Nutr Rev. 2004;62:1-17.

30. Tohill BC, Seymour J, Serdula M, et al. What epidemiologic studies tell us about the relationship between fruit and vegetable consumption and body weight. Nutr Rev. 2004;62:365-374.

31. Caspi CE, Sorensen G, Subramanian SV, et al. The local food environment and diet: a systematic review. Health Place. 2012;18: 1172-1187.

32. Hanson NI, Neumark-Sztainer D, Eisenberg ME, et al. Associations between parental report of the home food environment and adolescent intakes of fruits, vegetables and dairy foods. Public Health Nutr. 2005:8:77-85.

33. Arcan C, Neumark-Sztainer D, Hannan $P$, et al. Parental eating behaviours, home food environment and adolescent intakes of fruits, vegetables and dairy foods: longitudinal findings from Project EAT. Public Health Nutr. 2007;10:1257-1265.

34. Ding D, Sallis JF, Norman GJ, et al. Community food environment, home food environment, and fruit and vegetable intake of children and adolescents. J Nutr Educ Behav. 2012;44:634-638.

35. Caldwell EM, Miller Kobayashi M, DuBow WM, et al. Perceived access to fruits and vegetables associated with increased consumption. Public Health Nutr. 2009;12:1743-1750.

36. Dubowitz T, Ghosh-Dastidar M, Cohen DA, et al. Diet and perceptions change with supermarket introduction in a food desert, but not because of supermarket use. Health Aff (Millwood). 2015;34: 1858-1868.

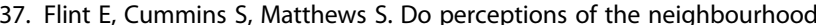
food environment predict fruit and vegetable intake in low-income neighbourhoods? Health Place. 2013;24:11-15.

38. Freedman DA, Bell BA. Access to healthful foods among an urban food insecure population: perceptions versus reality. J Urban Health. 2009;86:825-838.

39. Giskes K, Van Lenthe FJ, Brug J, et al. Socioeconomic inequalities in food purchasing: the contribution of respondent-perceived and actual (objectively measured) price and availability of foods. Prev Med. 2007;45: 41-48.

40. Inglis V, Ball K, Crawford D. Socioeconomic variations in women's diets: what is the role of perceptions of the local food environment? J Epidemiol Community Health. 2008;62:191-197.

41. Moore LV, Diez Roux AV, Brines S. Comparing perception-based and geographic information system (GIS)-based characterizations of the local food environment. J Urban Health. 2008;85:206-216.

42. Moore LV, Diez Roux AV, Nettleton JA, et al. Associations of the local food environment with diet quality - a comparison of assessments based on surveys and geographic information systems: the multi-ethnic study of atherosclerosis. Am J Epidemiol. 2008;167:917-924.

43. Sharkey JR, Johnson CM, Dean WR. Food access and perceptions of the community and household food environment as correlates of fruit and vegetable intake among rural seniors. BMC Geriatr. 2010;10:32.

44. Caspi CE, Kawachi I, Subramanian SV, et al. The relationship between diet and perceived and objective access to supermarkets among low-income housing residents. Soc Sci Med. 2012;75:1254-1262.

45. Williams LK, Thornton L, Ball K, et al. Is the objective food environment associated with perceptions of the food environment? Public Health Nutr. 2012;15:291-298.

46. Barnes TL, Bell BA, Freedman DA, et al. Do people really know what food retailers exist in their neighborhood? Examining GIS-based and perceived presence of retail food outlets in an eight-county region of South Carolina. Spat Spatiotemporal Epidemiol. 2015;13:31-40.

47. Minnis AM, Catellier D, Kent C, et al. Differences in chronic disease behavioral indicators by sexual orientation and sex. J Public Health Manag Pract. 2016;22(Suppl 1):S25-S32.

48. United States Census Bureau. American Community Survey (ACS). Data Available at www.census.gov/programs-surveys/acs/data.html.

49. U.S. Department of Agriculture Economic Research Service. Food environment atlas. Available at www.ers.usda.gov/data-products/foodenvironment-atlas.aspx Accessed March 10, 2017. 
50. Belsley DA, Kuh E, Welsch RE. Regression Diagnostics: Identifying Influential Data and Sources of Collinearity. New York, NY: Wiley, 1980.

51. Hocking RR. Methods and Applications of Linear Models: Regression and the Analysis of Variance. Hoboken, NJ: Wiley, 2003.

52. Mandel J. Use of the singular decomposition in regression analysis. Am Stat. 1982;36:15-24.

53. Liao D, Valliant R. Variance inflation factors in the analysis of complex survey data. Surv Meth. 2012;38:53-62.

54. Do DP, Dubowitz T, Bird CE, et al. Neighborhood context and ethnicity differences in body mass index: a multilevel analysis using the NHANES III survey (1988-1994). Econ Hum Biol. 2007;5:179-203.

55. Dubowitz T, Zenk SN, Ghosh-Dastidar B, et al. Healthy food access for urban food desert residents: examination of the food environment, food purchasing practices, diet and BMI. Public Health Nutr. 2015;18: 2220-2230.

56. Vaughan CA, Collins R, Ghosh-Dastidar M, et al. Does where you shop or who you are predict what you eat? The role of stores and individual characteristics in dietary intake. Prev Med. 2017;100:10-16.

57. Wardle J, Parmenter K, Waller J. Nutrition knowledge and food intake. Appetite. 2000;34:269-275.
Cite this article as: Halpern MT, Arena LC, Royce RA, Soler RE, Munoz B, Hennessy CM (2017) Neighborhood and individual sociodemographic characteristics associated with disparities in adult obesity and perceptions of the home food environment, Health Equity 1:1, 139-149, DOI: $10.1089 /$ heq.2017.0010.

\section{Abbreviations Used}

ATSS $=$ Adult Targeted Surveillance Survey

$\mathrm{BMI}=$ body mass index

$\mathrm{CDC}=$ Centers for Disease Control and Prevention

$\mathrm{Cl}=$ confidence interval

$\mathrm{CTG}=$ Community Transformation Grant

$\mathrm{IQR}=$ interquartile range

$\mathrm{OR}=$ odds ratio

$\mathrm{SES}=$ socioeconomic status

USDA = U.S. Department of Agriculture

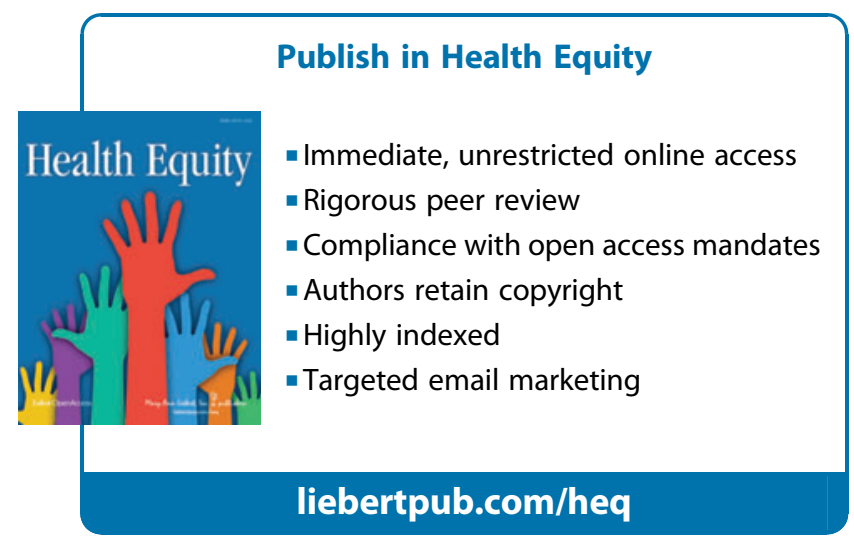

